\title{
Influence of Antimicrobial Nanoparticles on Flexural Strength and Hardness of Polymethylmethacrylate
}

\author{
Mennatullah Khalil ${ }^{1 *}$ (D), Lamis Enaba ${ }^{2}$ (D) \\ ${ }^{1}$ Department of Dental Biomaterials, Faculty of Dentistry, Fayoum University, Faiyum, Egypt; ${ }^{2}$ Department of Dental Biomaterials, \\ Faculty of Dentistry, Misr International University, Cairo, Egypt
}

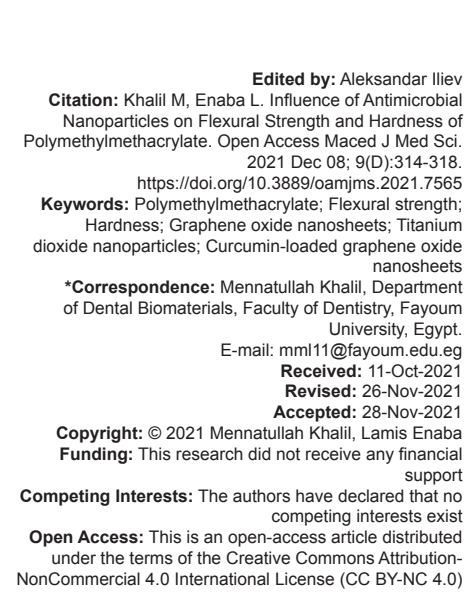

Introduction

Polymethylmethacrylate (PMMA) is a popular and versatile dental material used mainly for removable dental appliances [1]. Its wide use and acceptance in dentistry are due to its excellent esthetics, low cost, availability, ease of processing, and repair [2]. Although, PMMA displays desirable properties several shortcomings have created high demand for the development of a modified version of the material.

One shortcomings of PMMA is that its contamination and accumulation of microbes from the oral environment adversely affects the health of patients [2], [3]. Several attempts have been made at improving the properties of PMMA and giving it antimicrobial characteristics through different additions, including the use of nanomaterials [2], [3], [4].

Using nanoparticles (NPs) is helpful in creating an antimicrobial PMMA and combating the potential problem of microbes adhering to dental appliances [1].
NPs combined with polymers such as PMMA were found to exhibit superior antimicrobial properties in the oral cavity [5].

Despite the importance of developing a PMMA with antimicrobial resistance, it is crucial not to compromise the mechanical properties of the appliance. Mechanical properties are important for the evaluation and determination of the longevity, and quality of service provided by an appliance. Higher mechanical properties will allow the resistance of; uneven masticatory forces present in the oral cavity, scratches, wear, and sudden fractures [4], [6], [7].

The purpose of this study was to modify PMMA with three different antimicrobial NPs; Graphene oxide nanosheets (nGO), Titanium dioxide NPs ( $\mathrm{TiO}_{2} \mathrm{NPs}$ ), and Curcumin (CUR) loaded graphene oxide nanosheets (nGOCUR) alone, and in combination, and assessing the flexural strength and hardness of the different groups. The modified groups were compared to the unmodified PMMA and each other. 


\section{Material}

Chemically cured acrylic resin material composed of PMMA powder and methylmethacrylate liquid (Acrostone, Egypt) was used as the polymeric base of the denture base material. Titanium (IV) isopropoxide, 97\% (Alfa Aesar), Graphite powder (extra pure, TM Media, India), and CUR (crystalline 99\%, Loba Chemie) were prepared into nanomaterials and used as inorganic fillers to modify the denture base material. The inorganic fillers were prepared in Nano Gate lab, Cairo, Egypt.

\section{Preparation of the inorganic fillers.}

\section{Graphene oxide nanosheets (nGO)}

The improved hummer method was used to prepare the $\mathrm{GO}$ nanosheets. $\mathrm{KMnO}_{4}$ was added slowly in 6 equal portions to a 9:1 mixture of concentrated $\mathrm{H}_{2} \mathrm{SO}_{4} / \mathrm{H}_{3} \mathrm{PO}_{4}$ and graphite flakes, producing a slight exothermic reaction $\left(35-40^{\circ} \mathrm{C}\right)$. The reaction mixture was then heated to $50^{\circ} \mathrm{C}$ and stirred for $12 \mathrm{~h}$ and then it was cooled to room temperature and poured onto ice containing $30 \% \mathrm{H}_{2} \mathrm{O}_{2}$. It was then neutralized by multiple washings with distilled water and then centrifugated at $4000 \mathrm{rpm}$ for $4 \mathrm{~h}$ resulting in supernatant material that was decanted. The residual material left behind was washed in sequence with $200 \mathrm{ml}$ distilled $\mathrm{H}_{2} \mathrm{O} 3$ times, $200 \mathrm{ml}$ of $30 \% \mathrm{HCl}$ and $200 \mathrm{ml}$ of ethanol 2 times. The solution was then filtered using the U.S. Standard testing sieve and then filtered through polyester fiber membrane and the obtained product was dried in vacuum for $48 \mathrm{~h}$ at $45^{\circ} \mathrm{C}$ [8]

\section{Titanium Dioxide (TiO2) Nanoparticles}

$\mathrm{TiO}_{2}$ NPs were prepared by hydrolysis of titanium (IV) isopropoxide in propan-2-ol at $80^{\circ} \mathrm{C}$ for $4 \mathrm{~h}$. The colloidal suspensions were adjusted to low $\mathrm{pH}$ using nitric acid $\left(\mathrm{HNO}_{3}\right)$ and then additionally heated at $80^{\circ} \mathrm{C}$ for $24 \mathrm{~h}$. The final form was a powder of spherical particles with an average size of $15 \pm 3 \mathrm{~nm}$ constituting 95-97\% anatase and 3-5\% brookite [9], [10].

\section{Curcumin Loaded Graphene Oxide Nanosheets (nGOCUR)}

The loading of CUR on nGOs was carried out by mixing $\mathrm{GO}$ in $\mathrm{ddH}_{2} \mathrm{O}$ at a concentration of $2 \mathrm{mg} / \mathrm{ml}$ with $2 \mathrm{ml}$ CUR dissolved in ultrapure ethanol at a concentration of $300 \mu \mathrm{g}$. The samples were incubated at $70^{\circ} \mathrm{C}$ for $12 \mathrm{~h}$ for complete ethanol evaporation [11], [12].

The inorganic fillers were mixed with the acrylic resin powder of PMMA using a mixing mill for 15 min to get a homogenous distribution of the phases [13].
Table 1: PMMA and its modifications

\begin{tabular}{ll}
\hline Group & Composition \\
\hline $\mathrm{A}$ & PMMA \\
$\mathrm{B}$ & PMMA $50 \mathrm{~g} / \mathrm{GO} 0.001 \mathrm{~g}$ \\
$\mathrm{C}$ & PMMA $50 \mathrm{~g} / \mathrm{TiO}{ }_{2} 0.5 \mathrm{~g}$ \\
$\mathrm{D}$ & PMMA $50 \mathrm{~g} / \mathrm{TiO}{ }_{2} 0.5 \mathrm{~g} / \mathrm{GO} 0.001 \mathrm{~g}$ \\
$\mathrm{E}$ & PMMA $50 \mathrm{~g} / \mathrm{GOCUR} 0.001 \mathrm{~g}$ \\
$\mathrm{~F}$ & PMMA $50 \mathrm{~g} / \mathrm{TiO}_{2} 0.5 \mathrm{~g} / \mathrm{GOCUR} 0.001 \mathrm{~g}$ \\
\hline
\end{tabular}

(Table 1) shows the different groups prepared in the study with the amount in grams of PMMA and inorganic fillers in each group.

\section{Methods}

\section{Sample size calculation}

Sample size calculation was performed using the G-power test and ANOVA test was used for comparison according to a previous study by Zidan et al. in 2019 [14].

In the flexural strength test, a total of 42 samples (7 in each group) were sufficient to detect a large effect size of 0.65 with a power of 0.8 and a $p \leq 0.05$. In the hardness test, a total of 36 samples ( 6 in each group) were sufficient to detect a large effect size of 0.7 with a power of 0.8 and $a p \leq 0.05$.

\section{Specimen preparation}

A total of 78 specimens were prepared for the tests conducted. The molds were made from an aluminum alloy with cavities with the dimensions of $65 \mathrm{~mm}$ (length) $\times 10 \mathrm{~mm}$ (width) $\times 2.5 \mathrm{~mm}$ (depth) The powder in each group was mixed with the liquid monomer according to manufacturers' instructions, mixing was continued until a consistent mixture was obtained. When the mixture reached the dough stage, it was packed inside the molds.

Before pouring the mixture into the mold, a separating medium of sodium alginate was applied to the mold for easy separation. The mix was left to set completely and then removed from the mold [14].

\section{Flexural strength test}

The flexural strength (MPa) of the specimens was evaluated using the 3-point bending test in a universal testing machine (Model STM-50, Santam, Tehran, Iran) with a cross-head speed of $5 \mathrm{~mm} / \mathrm{min}$. The 42 specimens ( 7 in each group) were stored in distilled water at room temperature for 10 days and then retrieved and placed on supporting jigs $40 \mathrm{~mm}$ apart. A loading force was applied using a centrally located plunger with a diameter of $20 \mathrm{~mm}$ and the maximum load exerted on the specimens until fracture was recorded. The flexural strength was calculated as $\mathrm{F}=3 \mathrm{PL} / 2 \mathrm{bd}^{2}$, where $\mathrm{F}$ is the 
flexural strength, $P$ is the applied load, $L$ is the support span length, $b$ is the sample with and $d$ is the sample thickness [6], [14].

\section{Hardness test}

A total of 36 specimens (6 in each group) were evaluated using a fully automatic Vicker hardness $\left(\mathrm{HV}_{0.05}\right)$ testing machine (Tukon 1102, Wilson, Buehler, Germany). The indenter had a square-based diamond pyramid and the value of the load was fixed at $50 \mathrm{~g}$ for $10 \mathrm{~s}$. The load was applied smoothly, without impact, and after removal, the indentation was observed with a magnifying lens and the two impression diagonals were measured (to the nearest $0.1-\mu \mathrm{m})$ and averaged. The Vickers hardness (HV) was calculated as $\mathrm{HV}=1854.4 \mathrm{~L} / \mathrm{d}^{2}$, where $\mathrm{L}$ is the load and $d$ is the averaged diagonals [6], [14].

\section{Statistical analysis}

Statistical analysis was performed using SPSS 16.0 (Statistical Package for Scientific Studies, SPSS, Inc., Chicago, IL, USA) for Windows. The data were expressed as means and standard deviation and it was explored for normality using the Kolmogorov-Smirnov test of normality. The results of Kolmogorov-Smirnov test indicated that most of the data were normally distributed (parametric data), so one-way analysis of variance ANOVA test was used to compare between groups, followed by Bonferroni's post hoc test for pairwise comparison. The significance level was set at $p \leq 0.05$.

\section{Results}

\section{Flexural strength}

The highest mean value for flexural strength (MPa) was recorded in Group C $(52.26 \pm 5.48 \mathrm{MPa})$ and the lowest value was in group A (24.94 $\pm 5.37 \mathrm{MPa})$. There was a statistically significant difference between all tested groups $(p=0.00)$ (Table 2$)$.

\section{Microhardness}

The highest mean value for microhardness (HV) was recorded in Group F (23.29 $\pm 0.8 \mathrm{HV})$ and the

Table 2: Mean flexural strength (MPa) of each group and comparison between them

\begin{tabular}{llll}
\hline Group & Mean & Standard deviation & $\mathrm{p}$ \\
\hline $\mathrm{A}$ & $24.94^{\mathrm{d}}$ & 5.37 & $0.000^{*}$ \\
$\mathrm{~B}$ & $35.54^{\mathrm{b}, \mathrm{c}}$ & 4.26 & \\
$\mathrm{C}$ & $52.26^{\mathrm{a}}$ & 5.48 & \\
$\mathrm{D}$ & $43.29^{\mathrm{b}}$ & 6.46 & \\
$\mathrm{E}$ & $42.58^{\mathrm{b}}$ & 3.12 & \\
$\mathrm{~F}$ & $31.59^{\mathrm{c}, \mathrm{d}}$ & 4.80 & \\
\hline Significance level $\mathrm{p}<0.05,{ }^{*}$ Significant. Bonferroni post hoc test for pair-wise comparison, the means \\
sharing the same superscript letter are not significantly different.
\end{tabular}

lowest value was in group A $(15.88 \pm 1.02 \mathrm{HV})$. There was a statistically significant difference between all tested groups $(p=0.00)$ (Table 3$)$.

Table 3: Mean microhardness (HV) of each group and comparison between them

\begin{tabular}{llll}
\hline Group & Mean & Standard deviation & $\mathrm{p}$ \\
\hline $\mathrm{A}$ & $15.88^{\mathrm{d}}$ & 1.02 & $0.000^{*}$ \\
$\mathrm{~B}$ & $19.07^{\mathrm{b}, \mathrm{c}}$ & 0.89 & \\
$\mathrm{C}$ & $18.45^{\mathrm{c}}$ & 1.04 & \\
$\mathrm{D}$ & $18.13^{\mathrm{c}}$ & 0.63 & \\
$\mathrm{E}$ & $20.32^{\mathrm{b}}$ & 0.34 & \\
$\mathrm{~F}$ & $23.29^{\mathrm{a}}$ & 0.80 & \\
\hline Significance level $\mathrm{p}<0.05,{ }^{*}$ Significant. Bonferroni post hoc test for pair-wise comparison, the means \\
\multicolumn{5}{l}{ sharing the same superscript letter are not significantly different. }
\end{tabular}

\section{Discussion}

NPs range in size between 1 and $100 \mathrm{~nm}$ and have very promising antimicrobial activity. This activity is attributed to its small size, large surface area to volume ratio, and increased chemical reactivity. NPs are incorporated in dental materials because their large surface area and high charge density enable them to interact with bacterial cells that are negatively charged causing antibacterial activity [1]. The addition of NP as fillers also influences other properties of the modified material including its mechanical properties.

PMMA is an acrylic resin that is commonly used when fabricating an appliance's denture base. These resins could benefit from the application of NPs to improve their properties especially mechanically. A study by Gad et al. in 2016 found that the addition of NPs improved the mechanical and physical properties of acrylic resin [7].

In this study, different metal oxide NPs with proven antimicrobial effects were added to chemically cured PMMA to avoid thermal damage to the fillers during heat-induced polymerization. The flexural strength and hardness of the modified PMMA (Group B, C, D, E, and $F$ ) were tested and compared to unmodified PMMA (Group A) and each other. These two mechanical properties were tested because low flexural strength is one of the major causes of denture base failure while low scratch resistance can lead to scratches which can accumulate plaque and weaken the base [3].

nGOs were used as fillers in the PMMA because of their biocompatibility, high mechanical properties, and proven antimicrobial activity against oral bacteria and fungus [15], [16], [17]. A study by Lee et al. in 2018 incorporated nGO into PMMA and found that it roughened its surface and increased its hydrophilicity without compromising its flexural strength and surface hardness. The nGO incorporated PMMA was tested against 4 microorganisms commonly found in the oral environment and was found to have an antimicrobial effect against all four species [3].

In this study, the addition of nGO to the PMMA (Group B) increased its flexural strength and hardness 
significantly compared to the unmodified PMMA. This is due to the higher elastic modulus of the $\mathrm{nGO}$ which reinforced the PMMA [18]. Despite the low percentage of nGO dispersed in the PMMA, it could increase the mechanical properties significantly by reducing stress concentration in the matrix [19].

$\mathrm{TiO}_{2}$ has been incorporated in various biomaterials including composites because of their antimicrobial effectiveness and the ability to produce self-cleaning dental materials. A study by Sodagar et al. in 2016 assessed the effectiveness of nanotitanium dioxide and nanosilicone dioxide against cariogenic bacteria and they were found to show strong antimicrobial activity [20].

In this study, the group with the $\mathrm{TiO}_{2} \mathrm{NPs}$ added to PMMA (Group C) showed a significant increase in flexural strength and hardness. The results could also be due to an increase in the number of bonds between the matrix and the fillers which require more energy to break increasing the mechanical properties over all of the modified PMMA [21].

A study by Hashem et al. in 2017 found that the modification of PMMA with $1 \%, 2 \%$, and $3 \% \mathrm{TiO}_{2}$ NPs resulted in increased hardness values of the tested material by $20 \%, 30 \%$ while the flexural strength increased by $95 \%$. This increase could be due to the NPs acting as rigid bodies in the PMMA matrix, therefore increasing the stiffness and reducing the mobility of the matrix [22].

In this study both $\mathrm{nGO}$ and $\mathrm{TiO}_{2}$ NPs were added each on their own (Group $B$ and $C$ ) and together (Group D) to PMMA. All 3 groups gave a modified material with higher flexural strength properties and surface hardness compared to the unmodified materials.

CUR is a low molecular weight polyphenol with antimicrobial effects and antifungal potential. The problem with the clinical use of CUR is its insolubility in water, limiting its bioavailability and stability. To improve its properties it should be encapsulated in a drug delivery system [23].

A study by Sodagar et al. in 2016, 1\% CUR NP was added to orthodontic composite and the antimicrobial effect and shear bond strength were assessed. It was found that the composite had significant antimicrobial activity against cariogenic bacteria and there was no adverse effect on the shear bond strength. The major drawback to the use of the CUR NPs was their insolubility [24].

In this study $\mathrm{nGO}$, is used as the drug delivery system for CUR and added to PMMA (Group E). As far as we know this is the first study to modify PMMA by incorporating nGOCUR. This modification could be very beneficial because denture base materials could positively benefit from having a drug with antimicrobial potential. After testing the mechanical properties of this group it was found that it was still significantly higher than PMMA and also higher than the nGO without the CUR. The addition of the drug to the nGO positively affected the strength properties.

Another modification was also tested in this study both $\mathrm{TiO}_{2} \mathrm{NP}$ and nGOCUR were added to PMMA (Group F). This combination of NPs reduced the flexural strength of the PMMA where it was the lowest of all the modified groups and although it was higher than the unmodified PMMA (Group A) the increase was not significant. On the other hand, the hardness in this group was found to be significantly the highest among all the groups. This could mean that the combination of NPs increased the surface bond strength of the particles but negatively affected the bulk of the specimen. It could also be due to excess air bubbles in the body of the specimen during the mixing of the polymer powder and liquid.

\section{Conclusion}

Within the limitations of this study, it can be concluded that the modification of PMMA with NPs with proven antimicrobial activity can increase the flexural strength and hardness of the material. $\mathrm{GO}, \mathrm{TiO}_{2}$, and GOCUR NPs were each used alone and in different combinations, and all the groups displayed higher flexural strength and hardness than the unmodified PMMA. This increase in mechanical properties could be because of the higher modulus of elasticity of the NPs or an increase in the number of bonds between the matrix and the fillers. No direct relationship was found between increasing the number and types of NPs and an increase in both flexural strength and hardness.

\section{References}

1. Alrahlah A, Fouad $H$, Hashem M, Niazy A, AlBadah A. Titanium oxide (TiO2)/polymethylmethacrylate (PMMA) denture base nanocomposites: Mechanical, viscoelastic and antibacterial behavior. Materials. 2018;11(7):1096. https://doi.org/10.3390/ ma11071096

PMid:29954116

2. Totu EE, Nechifor AC, Nechifor G, Aboul-Enein HY, Cristache CM Poly (methyl methacrylate) with $\mathrm{TiO}_{2}$ nanoparticles inclusion for stereolitographic complete denture manufacturing-the fututre in dental care for elderly edentulous patients? J Dent. 2017;59:6877. https://doi.org/10.1016/j.jdent.2017.02.012 PMid:28223199

3. Lee JH, Jo JK, Kim DA, Patel KD, Kim HW, Lee HH. Nanographene oxide incorporated into PMMA resin to prevent microbial adhesion. Dent Mater. 2018;34(4):e63-72. https://doi. org/10.1016/j.dental.2018.01.019

PMid:29402540

4. Thomas R, Snigdha S, Bhavitha KB, Babu S, Ajith A, Radhakrishnan EK. Biofabricated silver nanoparticles 
incorporated polymethyl methacrylate as a dental adhesive material with antibacterial and antibiofilm activity against Streptococcus mutans. 3 Biotech. 2018;8(9):404. https://doi. org/10.1007/s13205-018-1420-y

PMid:30221117

5. Song W, Ge S. Application of antimicrobial nanoparticles in dentistry. Molecules. 2019;24(6):1033. https://doi.org/10.3390/ molecules 24061033

PMid:30875929

6. Lee HH, Lee CJ, Asaoka K. Correlation in the mechanical properties of acrylic denture base resins. Dent Mater J. 2012;31(1):157-64. https://doi.org/10.4012/dmj.2011-205 PMid:22277620

7. Gad MM, Al-Thobity AM, Rahoma A, Abualsaud R, Al-Harbi FA, Akhtar S. Reinforcement of PMMA denture base material with a mixture of $\mathrm{ZrO}_{2}$ nanoparticles and glass fibers. Int J Dent. 2019;2019:2489393. https://doi.org/10.1155/2019/2489393 PMid:30809260

8. Marcano DC, Kosynkin DV, Berlin JM, Sinitskii A, Sun Z, Slesarev A, et al. Improved synthesis of graphene oxide. ACS Nano. 2010;4(8):4806-14. https://doi.org/10.1021/nn1006368 PMid:20731455

9. Vorkapic D, Matsoukas T. Effect of temperature and alcohols in the preparation of titania nanoparticles from alkoxides. J Am Ceram Soc. 1998;81(11):2815-20. https://doi. org/10.1111/j.1151-2916.1998.tb02701.x

10. MahshidS,AskariM, GhamsariMS.SynthesisofTiO ${ }_{2}$ nanoparticles by hydrolysis and peptization of titanium isopropoxide solution. J Mater Process Technol. 2007;189(1-3):296-300. https://doi. org/10.1016/j.jmatprotec.2007.01.040

11. Hatamie S, Akhavan O, Sadrnezhaad SK, Ahadian MM, Shirolkar MM, Wang HQ. Curcumin-reduced graphene oxide sheets and their effects on human breast cancer cells. Mater Sci Eng C Mater Biol Appl. 2015;55:482-9. https://doi.org/10.1016/j. msec.2015.05.077

PMid:26117780

12. Bugli F, Cacaci M, Palmieri V, Di Santo R, Torelli R, Ciasca G, et al. Curcumin-loaded graphene oxide flakes as an effective antibacterial system against methicillin-resistant Staphylococcus aureus. Interface Focus. 2018;8(3):20170059. https://doi. org/10.1098/rsfs.2017.0059 PMid:29696091

13. Alamgir M, Tiwari SK, Mallick A, Nayak GC. Graphene oxide and $\mathrm{TiO} 2$ based PMMA nanocomposites for dental applications: A comprehensive study of the mechanical properties. In: IOP Conference Series: Materials Science and Engineering. Vol. 377. Bristol, United Kingdom: IOP Publishing 2018. p. 012082.

14. Zidan S, Silikas N, Alhotan A, Haider J, Yates J. Investigating the mechanical properties of ZrO2-impregnated PMMA nanocomposite for denture-based applications. Materials (Basel). 2019;12(8):1344. https://doi.org/10.3390/ma12081344 PMid:31027157

15. Gamal R, Gomaa YF, Said AM. Incorporating nano graphene oxide to poly-methyl methacrylate; antibacterial effect and thermal expansion. J Mod Res. 2019;1(1):19-23. https://doi. org/10.21608/JMR.2019.14281.1003

16. He J, Zhu X, Qi Z, Wang L, Aldalbahi A, Shi J, et al. The inhibition effect of graphene oxide nanosheets on the development of Streptococcus mutans biofilms. Part Part Syst Characterizat. 2017;34(5):1700001. https://doi.org/10.1002/ppsc.201700001

17. Lee SM, Yoo KH, Yoon SY, Kim IR, Park BS, Son WS, et al. Enamel anti-demineralization effect of orthodontic adhesive containing bioactive glass and graphene oxide: An in vitro study. Materials (Basel). 2018;11(9):1728. https://doi.org/10.3390/ ma11091728 PMid:30223468

18. Kavimani V, Prakash KS, Thankachan T, Udayakumar R. Synergistic improvement of epoxy derived polymer composites reinforced with graphene oxide (GO) plus titanium di oxide (TiO2). Compos B Eng. 2020;191:107911. https://doi. org/10.1016/j.compositesb.2020.107911

19. Sava S, Moldovan M, Sarosi C, Mesaros A, Dudea D, Alb C. Effects of graphene addition on the mechanical properties of composites for dental restoration. Mater Plast. 2015;52:90-2.

20. Sodagar A, Khalil S, Kassaee MZ, Shahroudi AS, Pourakbari B, Bahador A. Antimicrobial properties of poly (methyl methacrylate) acrylic resins incorporated with silicon dioxide and titanium dioxide nanoparticles on cariogenic bacteria. J Orthod Sci. 2016;5(1):7-13. https://doi.org/10.4103/2278-0203.176652 PMid:26998471

21. Mosalman S, Rashahmadi S, Hasanzadeh R. The effect of $\mathrm{TiO}_{2}$ nanoparticles on mechanical properties of poly methyl methacrylate nanocomposites (research note). Int J Eng. 2017;30(5):807-13.

22. Hashem M, Rez MF, Fouad H, Elsarnagawy T, Elsharawy MA, Umar A, et al. Influence of titanium oxide nanoparticles on the physical and thermomechanical behavior of poly methyl methacrylate (PMMA): A denture base resin. Sci Adv Mater. 2017;9(6):938-44. https://doi.org/10.1166/sam.2017.3087

23. Gutierrez JK, Zanatta GC, Ortega AL, Balastegui MI, Sanita PV, Pavarina AC, et al. Encapsulation of curcumin in polymeric nanoparticles for antimicrobial photodynamic therapy. PLoS One. 2017;12(11):e0187418. https://doi.org/10.1371/journal. pone.0187418 PMid:29107978

24. Sodagar A, Bahador A, Pourhajibagher M, Ahmadi B, Baghaeian P. Effect of addition of curcumin nanoparticles on antimicrobial property and shear bond strength of orthodontic composite to bovine enamel. J Dent (Tehran). 2016;13(5):373-82. PMid:28127332 